\title{
Bromodomain-Containing Protein 4 (BRD4) Inhibition Sensitizes Palomid 529-Induced Anti-Renal Cell Carcinoma Cell Activity in Vitro and in Vivo
}

\author{
Zhao-yu Xing $^{\mathrm{a}}$ Yin Wang $^{\mathrm{b}}$ Long Cheng ${ }^{\mathrm{c}}$ Jie Chen ${ }^{\mathrm{d}}$ Xiao-zhou He ${ }^{\mathrm{a}}$ Wei Xing ${ }^{\mathrm{d}}$ \\ aThe Department of Urology, the Third Affiliated Hospital, Soochow University, Changzhou, 'Dnstitute \\ of Neuroscience, Soochow University, Suzhou, 'Department of Interventional Radiology, the Second \\ Affiliated Hospital of Soochow University, Suzhou, dThe Department of Radiology, the Third Affiliated \\ Hospital, Soochow University, Changzhou, China
}

\section{Key Words}

Renal cell carcinoma $\cdot$ mTOR $•$ Palomid $529 \cdot$ BRD4 $\bullet$ Chemo-sensitization

\begin{abstract}
Background/Aims: Mammalian target of rapamycin (mTOR) is a valuable treatment target of renal cell carcinoma (RCC). Palomid 529 is a novel mTORC1/2 dual inhibitor. Methods: RCC cells were treated with different concentrations of Palomid 529. Cell survival was tested by MTT assay and clonogenicity assay. Cell proliferation was tested by BrdU ELISA assay. Cell apoptosis was tested by the Hoechst-33342 nuclei staining assay and Histone DNA ELISA assay. mTOR signaling was tested by Western blotting assay and co-immunoprecipitation (IP) assay. The SCID mouse 786-O xenograft model was established to test RCC cell growth in vivo. Results: Palomid 529 exerted cytotoxic, anti-proliferative and pro-apoptotic activities in 786-O RCC cells. Palomid 529 disassembled mTORC1/2, causing de-phosphorylation of mTORC1/2 substrates. Bromodomain-containing protein 4 (BRD4) is a primary resistant factor of Palomid 529. Palomid 529-induced 786-O cell apoptosis was sensitized by BRD4 inhibitors or BRD4 silencing, but inhibited with BRD4 over-expression. Palomid 529-induced cytotoxicity in the primary human RCC cells was negatively correlated with BRD4 expression level. In vivo, Palomid 529 i.p. administration inhibited 786-O xenograft tumor growth in SCID mice. Its anti-tumor activity was further sensitized by co-administration of the BRD4 inhibitor JQ1. Cconclusion: Palomid 529 inhibits RCC cell growth in vitro and in vivo. BRD4 inhibition could further sensitize Palomid 529 against RCC cells.
\end{abstract}




\section{Cellular Physiology Cell Physiol Biochem 2018;50:640-653 \begin{tabular}{ll|l} 
DOI: 10.1159/000494185 & $\begin{array}{l}\text { O } 2018 \text { The Author(s). Published by S. Karger AG, Basel } \\
\text { www.karger.com/cpb }\end{array}$ \\
\hline and Biochemistry
\end{tabular}}

Xing et al.: BRD4 Inhibition Sensitizes Palomid 529 in RCC Cells

\section{Introduction}

Renal cell carcinoma (RCC) is one common renal malignancy [1,2]. Mammalian target of rapamycin (mTOR) signaling is often hyper-activated in human RCC, which is involved in tumorigenesis and progression [3-5]. Therefore, mTOR is an important therapeutic target for human RCC [3-5]. There are two multiple-protein mTOR complexes [6, 7], including the MTOR complex 1 (mTORC1) and the mTOR complex 2 (mTORC2) [8]. mTORC1 is primarily formed by mTOR, PRAS40, Raptor, and mLST8 $[9,10]$. mTORC1 phosphorylates its main substrate proteins, p70S6K1 (S6K1) and eIF4E-binding protein 1 (4E-BP1) $[9,10]$. Rapamycin and its analogs (RAD001 and Everolimus etc) inhibit mTORC1 activation via binding to FK506binding protein 12 (FKBP12) $[9,10]$. mTORC2 is mainly composed of mTOR, Rictor and mSin1 [8-10]. mTORC2 acts as a kinase complex to phosphorylate several substrates, including AKT (at Ser-473) and other AGC kinases [11,12]. mTORC1 and mTORC2 are both important for RCC cell growth, proliferation, survival and apoptosis resistance, as well as angiogenesis and metastasis $[8,13]$. mTORC1 inhibition would lead to feedback activation of PI3K-AKT [14, 15] and ERK-MAPK pathways [16]. Recently, the mTOR kinase inhibitors were developed [17, 18]. These inhibitors block mTOR kinase activity to shutdown both mTORC1 and mTORC2 $[17,18]$. Palomid 529 is a novel mTORC1/2 dual inhibitor, which is able to disassociate both mTORC1 and mTORC2 [19-21]. The mTOR inhibitor could inhibit angiogenesis, vascular permeability and tumor growth in vitro and in vivo [21]. It can also sensitize the chemotherapy in hormone refractory prostate tumors [20]. The potential effect of Palomid 529 against human RCC cells is tested in the present study. Bromodomain-containing protein 4 (BRD4) is a key member of the bromodomain and extraterminal (BET) family proteins [22]. It has two N-terminal bromodomain and one extraterminal (ET) domain [23]. BRD4 binds directly to acetylated histones and transcription factors through bromodomain. It recruits multiple transcriptional regulators, including positives transcription elongation factor $\mathrm{b}$ (P-TEFb) and Mediator complex [23]. BRD4 mediates expression and activation of multiple oncogenes $[24,25]$. Our results here suggest that BRD4 could be a primary resistance factor of Palomid 529 in human RCC cells.

\section{Materials and Methods}

\section{Reagents and antibodies}

Palomid 529, JQ1, MS436 and CPI203 were purchased from Selleck (Shanghai, China). Palomid 529 was dissolved in DMSO [19]. Throughout the study, the final DMSO concentration was less than $0.05 \%$. The antibodies were provided by Cell Signaling Tech (Beverly, MA) and Santa Cruz Biotech (Suzhou, China). Puromycin was obtained from Sigma-Aldrich (St. Louis, MO). The cell culture reagents were provided by Gibco (Suzhou, China).

Culture of 786-O RCC cells

786-0 human RCC cells were provided by Dr. Zheng at Nantong University (Nantong, China) [26, 27].

\section{Primary culture of human RCC cells}

As described $[28,29]$, RCC tumor tissues were obtained from four RCC patients (male, 52/56/44/67year old, with no prior treatment) with tumor resection. The RCC patients were enrolled at the Affiliated Hospitals of Soochow University. RCC tumor tissues were confirmed by two specialized pathologists. Tissues were minced and digested via collagenase I (Sigma, $0.05 \% \mathrm{w} / \mathrm{v}$ ) incubation. Individual cells were pelleted, rinsed and filtered. Vascular cells and fibroblasts were abandoned. The remaining primary RCC cells were cultured in the described medium [29]. The using of human tissues was approved by the Ethics Review Board (ERB) of Soochow University. The written-informed consent was obtained from each enrolled patient. Studies were conducted according to the principles of Declaration of Helsinki. 


\section{Cellular Physiology Cell Physiol Biochem 2018;50:640-653 \begin{tabular}{ll|l} 
DOI: 10.1159/000494185 & $\begin{array}{l}\text { O 2018 The Author(s). Published by S. Karger AG, Basel } \\
\text { www.karger.com/cpb }\end{array}$
\end{tabular}}

Xing et al.: BRD4 Inhibition Sensitizes Palomid 529 in RCC Cells

MTT assay of cell survival

Briefly, cells (5, 000 cells per well) were plated onto the 96-well tissue-culture plates. Following the Palomid 529 treatment, cell viability was tested by the routine 3-[4, 5-dimethylthiazol-2-yl]-2, 5 diphenyltetrazolium bromide (MTT, Sigma) assay. MTT optical density (OD) was measured by a microplate reader (Bio-Rad, Basel, Switzerland) at $490 \mathrm{~nm}$.

\section{Clonogenicity assay}

786-0 cells were initially plated at 10,000 cells/well onto the six-well tissue-culture plate. Medium with Palomid 529 was renewed every two days for a total of 8 days. Afterwards, the number of remaining large colonies was counted.

BrdU assay

RCC cell proliferation via detection of BrdU incorporation was assessed through a commercial available ELISA kit (Cell Signaling, Shanghai, China). Briefly, RCC cells with the indicated treatment were incubated with BrdU $(10 \mu \mathrm{M})$. Afterwards, BrdU OD value at $450 \mathrm{~nm}$ was tested.

\section{Apoptosis ELISA assay}

Nucleosomal DNA fragmentation is a characteristic marker of cell apoptosis. The Histone-bound DNA was tested via a specific two-site enzyme-linked immunosorbent assay (ELISA) kit (Roche, Shanghai, China). Histone DNA ELISA OD at $450 \mathrm{~nm}$ was recorded.

Hoechst-33342 nuclei staining of apoptotic cells

Following the Palomid 529 treatment, RCC cells were stained with Hoechst-33342 dye (Sigma). Non-apoptotic nuclei were with faint delicate chromatin staining. Nuclei with intensified Hoechst-33342 condensation/brightness (early apoptotic cells) or fragmentation (late apoptotic cells) were labeled as apoptotic cells. Apoptotic nuclei percentage was calculated, from at least 200 cells of 5 random views $(1 \times 100)$ of each treatment.

\section{Western blotting assay}

The lysate proteins ( $30 \mu \mathrm{g}$ per lane of each treatment) were separated by $7.5-10 \%$ of SDS-PAGE gels, which were then transferred to PVDF membranes (Millipore, Wuxi, China). After blocking, the blots were incubated with primary and secondary antibodies. ECL detection kit was applied to detect the signals via $\mathrm{x}$-ray films. Quantification of the protein band was through the Image J software.

\section{Co-Immunoprecipitation (IP)}

As described [30,31], following the applied Palomid 529 treatment, $800 \mu \mathrm{g}$ protein lysates per sample were pre-cleared by the protein A/G Sepharose ("beads", Sigma). The pre-cleared lysates were then incubated with anti-mTOR antibody. Afterwards, $30 \mu \mathrm{L}$ of protein A/G beads were added again for 2 hours at $4{ }^{\circ} \mathrm{C}$. The beads were washed and tested by the Western blotting analysis [30, 31].

\section{Quantitative real-time PCR}

The total cellular RNA was extracted by the Trizol reagents (Sigma). High Capacity cDNA Reverse Transcription Kit was applied to synthesis cDNA from $2.0 \mu \mathrm{g}$ RNA (per sample). The Power SYBR Green RTPCR Reagents Kit was employed to perform the quantitative real-time PCR ("qRT-PCR") via the ABI-7600 FAST PCR system (Applied Biosystems, Foster, CA). We utilized the $2^{\triangle \Delta C t}$ method to calculate relative BRD4 mRNA expression (vs. GAPDH). BRD4 mRNA primers were described previously [32].

\section{shRNA-mediated gene knockdown}

Two lentiviral BRD4 shRNAs, with unique and non-overlapping sequences, were purchased from Sigma (SHCLNV-NM_058243, "BRD4 shRNA-1") and Santa Cruz Biotech (sc-43639-V, "BRD4 shRNA-2"). The lentiviral vector pLKO-1 containing c-MYC shRNA-1 (targeting sequence 1567-1585) and c-MYC shRNA-2 (targeting sequence 1341-1359) were provided by Genechem (Shanghai, China). shRNA lentivirus was 


\section{Cellular Physiology Cell Physiol Biochem 2018;50:640-653 \begin{tabular}{ll|l} 
DOI: 10.1159/000494185 & $\begin{array}{l}\text { O } 2018 \text { The Author(s). Published by S. Karger AG, Basel } \\
\text { www.karger.com/cpb }\end{array}$ \\
\cline { 2 - 3 } and Biochemistry
\end{tabular}}

Xing et al.: BRD4 Inhibition Sensitizes Palomid 529 in RCC Cells

added to 786-0 cells for 24 hours. Puromycin $(5.0 \mu \mathrm{g} / \mathrm{mL}$, Sigma) was then added to select the stable cells. BRD4/c-Myc knockdown in the stable cells was confirmed by Western blotting assay and/or qRT-PCR assay. Control cells were transfected with lentiviral scramble control shRNA (Santa Cruz).

\section{Exogenous BRD4 overexpression}

The pcDNA5-Flag-BRD4-WT-puro was purchased from Addgene (Plasmid \#90331, Shanghai, China). The construct was transfected to 786-0 cells using Lipofectamine 2000 (Invitrogen, Shanghai, China). Cells were then subjected to $5.0 \mu \mathrm{g} / \mathrm{mL}$ puromycin selection for 10-12 days. Exogenous and endogenous BRD4 expression in the stable cells were tested by Western blot assay.

\section{Xenograft model}

The male severe combined immunodeficiency (SCID) mice of 4 week old, 17-18g weight, were purchased from the Experimental Animal Center of Soochow University (Suzhou, China). To establish the xenograft tumor, 786-0 RCC cells $\left(5 \times 10^{6}\right.$ cells of each mouse) were injected subcutaneously (s.c.) to the right flanks. Tumors were established within three weeks with volume around $100 \mathrm{~mm}^{3}$. Mice ( $\mathrm{n}=10$ each group) were treated once every two days. Mice body weight and bi-dimensional tumor measurements were taken every 6 days for a total of 42 days. Tumor volume was measured as described [27]. The animal protocol was approved by the Institutional Animal Care and Use Committee (IACUC) and ERB of Soochow University (Suzhou, China). Mice in this study were observed on daily basis. Humane endpoints were applied to reduce suffering.

\section{Statistics}

Data were expressed as the mean \pm SD (standard deviation). Comparisons between groups were performed via one-way ANOVA (SPSS 18.0). $p$ values $<0.05$ were considered statistically significant. IC-50 was calculated by SPSS 18.0 .

\section{Results}

Palomid 529 exerts cytotoxic, anti-proliferative and pro-apoptotic activities in 786-O RCC cells

First, 786-0 RCC cells were treated with gradually-increased concentrations (0.1-10 $\mu \mathrm{M}$ ) of Palomid 529. MTT viability assay results in Fig. 1A demonstrate that Palomid 529 decreased 786-O cell viability in a dose- and time-dependent manner. At 72 hours, the IC-50, or the concentration that caused $50 \%$ reduction of cell viability, was $9.15 \pm 0.78 \mu \mathrm{M}$ (Fig. $1 \mathrm{~A})$. The clonogenicity assay was performed to further test the cytotoxic effect of Palomid 529. Quantified results in Fig. 1B show that the number of viable 786-0 colonies was significantly decreased following 1-10 $\mu \mathrm{M}$ of Palomid 529 treatment (At day-8). At a relative low concentration $(0.1 \mu \mathrm{M})$, Palomid 529 failed to affect 786-0 cell survival (Fig. $1 \mathrm{~A}$ and B).

The potential effect of Palomid 529 on cell proliferation was analyzed. BrdU incorporation ELISA assay [33] was performed, and results show that Palomid 529 dosedependently inhibited 786-0 cell proliferation (Fig. 1C). Apoptosis activation could be a primary mechanism of viability reduction and/or proliferation inhibition. As shown in Fig. 1D, Palomid 529 at 1-10 $\mu \mathrm{M}$ significantly increased the Histone-bound DNA ELISA OD, suggesting apoptosis activation. Additionally, the percentage of apoptotic nuclei was increased in Palomid 529 (1-10 $\mu \mathrm{M}$ )-treated 786-0 cells (Fig. 1E). Palomid 529 also induced cleavages of both PARP (Poly (ADP-ribose) polymerases) and caspase-9 in 786-0 cells (Fig. $1 \mathrm{~F}$ ). Palomid 529 at $0.1 \mu \mathrm{M}$ had no significant effect on cell apoptosis (Fig. 1D-F). Together, these results demonstrate that Palomid 529 exerts cytotoxic, anti-proliferative and proapoptotic activities in 786-0 cells. 


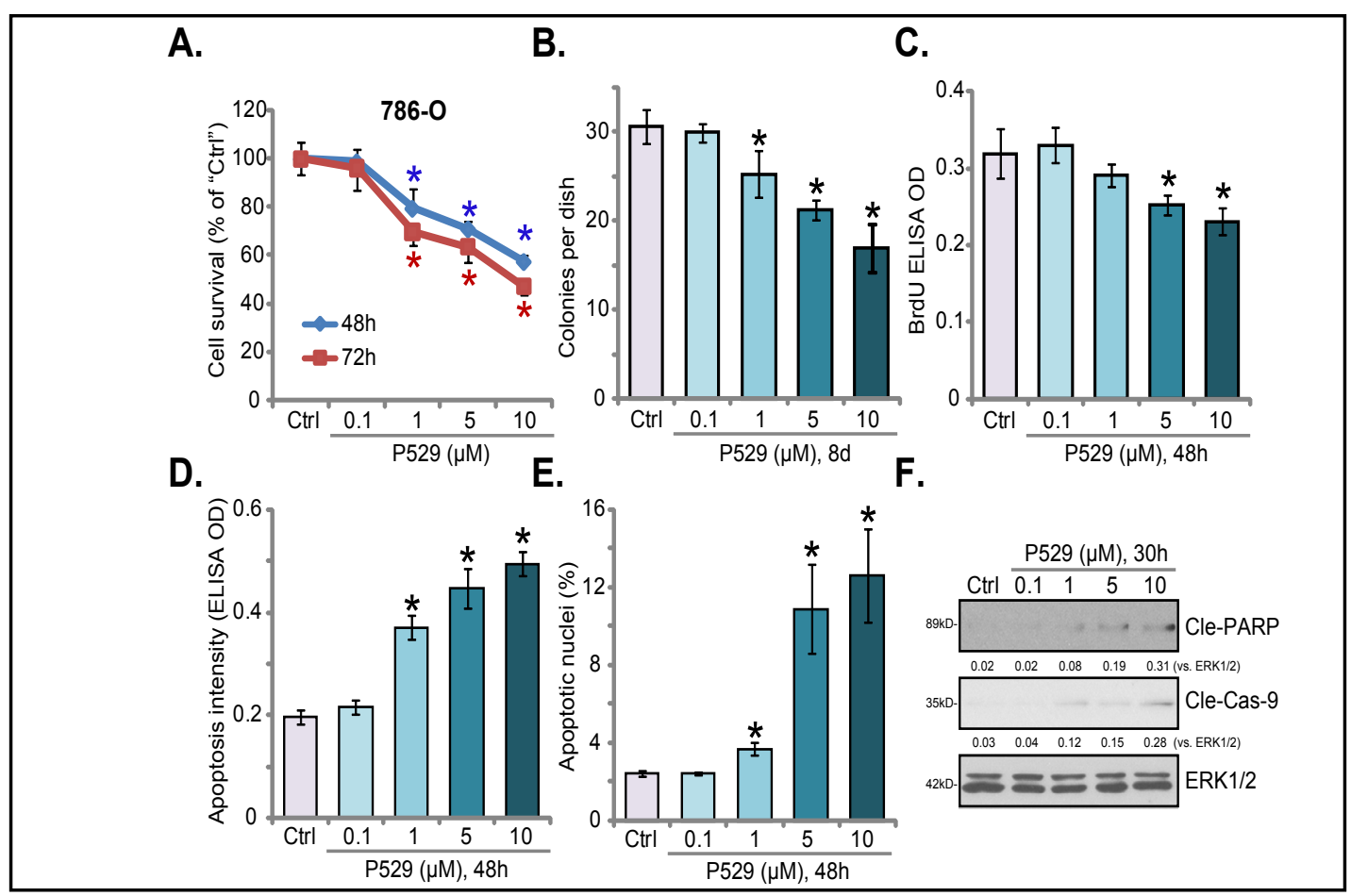

Fig. 1. Palomid 529 exerts cytotoxic, anti-proliferative and pro-apoptotic activities in 786-0 RCC cells. Cultured 786-0 RCC cells were either left untreated ("Ctrl") or treated with applied concentration (0.1-10 $\mu \mathrm{M}$ ) of Palomid 529 ("P529"), cells were then cultured in P529-containg medium for the applied time, cell survival was tested by the MTT assay (A) and clonogenicity assay (B, P529 medium was renewed every two days); Cell proliferation was tested by BrdU ELISA assay (C); Cell apoptosis was tested by the mentioned assays in the text (D-F). For blotting data in (F), expressions of cleaved-PARP ("Cle-PARP") and cleavedcaspase-9 ("Cle-Cas-9") were normalized to the loading control ERK1/2. Data were expressed as the mean \pm standard deviation (SD, same for all Fig.s). For each assay, $n=5$. * $p<0.05$ vs. "Ctrl" cells. In this figure, experiments were repeated three times, and similar results were obtained each time.

\section{Palomid 529 blocks mTORC1 and mTORC2 activation in 786-O cells}

mTOR activation in Palomid 529-treated cells was tested. S6 is a key substrate of mTORC1. AKT Ser-473 phosphorylation is the major substrate of mTORC2 [8, 10]. By performing the Western blotting assay, we show that Palomid 529 dose-dependently inhibited phosphorylation of S6 (Ser-235/236) and AKT (at Ser-473) in 786-0 cells (Fig. 2A). AKT Thr-308 phosphorylation was not affected (Fig. 2A), neither did ERK activation ("p-ERK1/2") (Fig. 2A).

By performing the co-immunoprecipitation ("IP") assay, we show that Palomid 529 (5 $\mu \mathrm{M}, 1$ hour) disrupted mTOR-Raptor association (the mTORC1 assembling [34]) and mTORRictor association (the mTORC2 assembling $[11,12]$ ) in 786-O cells (Fig. 2B, "IP" results). Expression of the mTOR complex components, including mTOR, Rictor and Raptor, were not affected by Palomid 529 treatment (Fig. 2B, "INPUT" results). These results indicate that Palomid 529 simantanuously blocks mTORC1 and mTORC2 activation in 786-0 cells.

\section{BRD4 inhibitors facilitate Palomid 529-induced 786-O cell apoptosis}

Recent studies have proposed a chemo-resistance activity of BRD4 [35, 36]. To test if BRD4 plays a similar role to Palomid 529, the BRD4 inhibitors were applied, including JQ1 [37, 38], MS436 [39] and CPI203 [40]. The BRD4 inhibitors significantly enhanced Palomid $529(5 \mu \mathrm{M})$-induced 786-O cell viability reduction (Fig. 3A) and apoptosis (Hoechst nuclei staining assay in Fig. 3B and Histone DNA apoptosis ELISA assay in Fig. 3C). Treatment with the BRD4 inhibitors alone only resulted in minor viability reduction (Fig. 3A) and apoptosis 
activation (Fig. 3B and C) in 786-0 cells. These results indicate that BRD4 inhibition might sensitize Palomid 529 in RCC cells.

BRD4 shRNA sensitizes Palomid
529-induced cytotoxicity in 786-O
cells
To exclude the possible off-target effect of the BRD4 inhibitors, shRNA strategy was employed to silence BRD4. Two different BRD4 shRNAs ("1/-2") were utilized, which led to over $90 \%$ BRD4 mRNA reduction in the stable 786-O cells (Fig. 4A). Western blotting assay results further confirmed significant BRD4 silencing by the targeted-shRNAs (Fig. 4B). BRD4 is essential for c-Myc expression [41], the latter is a key resistance factor in RCC cells [42]. Here, BRD4 silencing also led to significant c-Myc downregulation in 786-0 cells (Fig. 4B). BRD4 shRNA alone only induced minor cell viability reduction (Fig. 4C) and apoptosis (Fig. 4D). Importantly, Palomid 529-induced viability reduction (Fig. 4C) and apoptosis (Fig. 4D) were significantly enhanced in BRD4-silenced 786-0 cells. Palomid $529(5 \mu \mathrm{M})$ alone failed to affect BRD4 mRNA (Fig. 4A), BRD4 protein (Fig. 4B) and c-Myc protein (Fig. 4B) expression in 786-0 cells. Thus, BRD4 silencing sensitizes Palomid 529-induced cytotoxicity in 786-0 RCC cells.

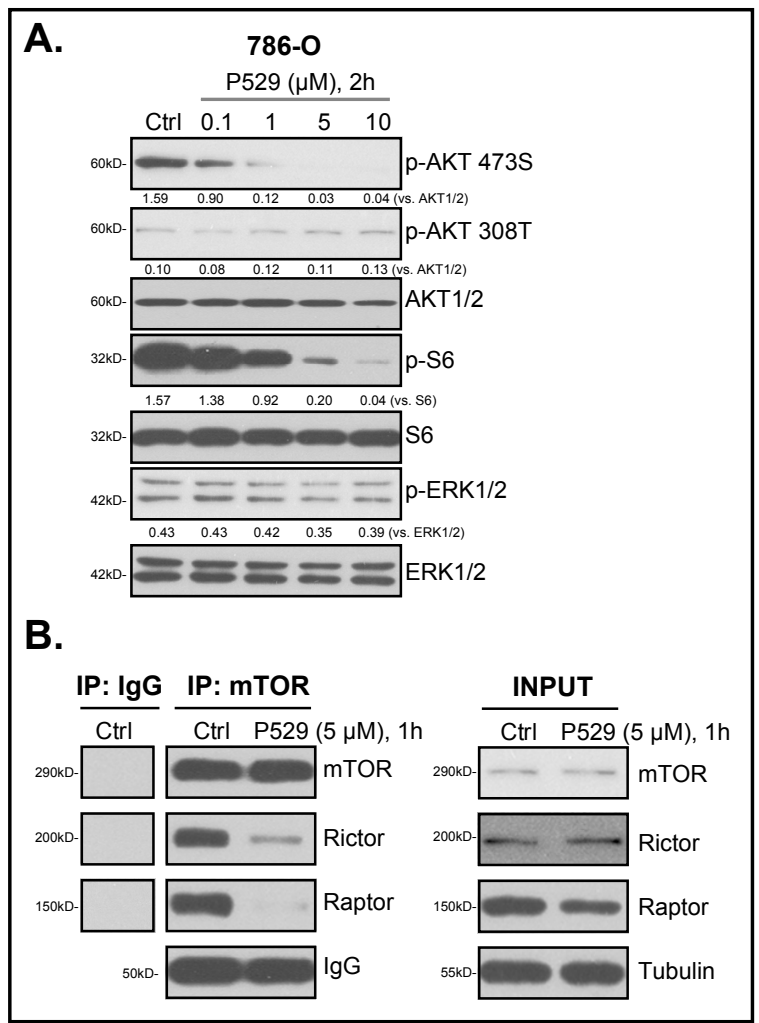

Fig. 2. Palomid 529 blocks mTORC1 and mTORC2 activation in 786-0 RCC cells. 786-0 cells were either left untreated ("Ctrl") or treated with applied concentration of Palomid 529 ("P529"), cells were then cultured in P529-containg medium for the applied time, expression of listed proteins in total cell lysates were tested by Western blotting assay (A); mTOR-bound proteins (Rictor and Raptor) were tested by co-immunoprecipitation (B, "IP") assay, and expression of mTOR signaling proteins (mTOR, Rictor and Raptor) was also tested (B, "INPUT"). In this figure, experiments were repeated three times, and similar results were obtained each time.

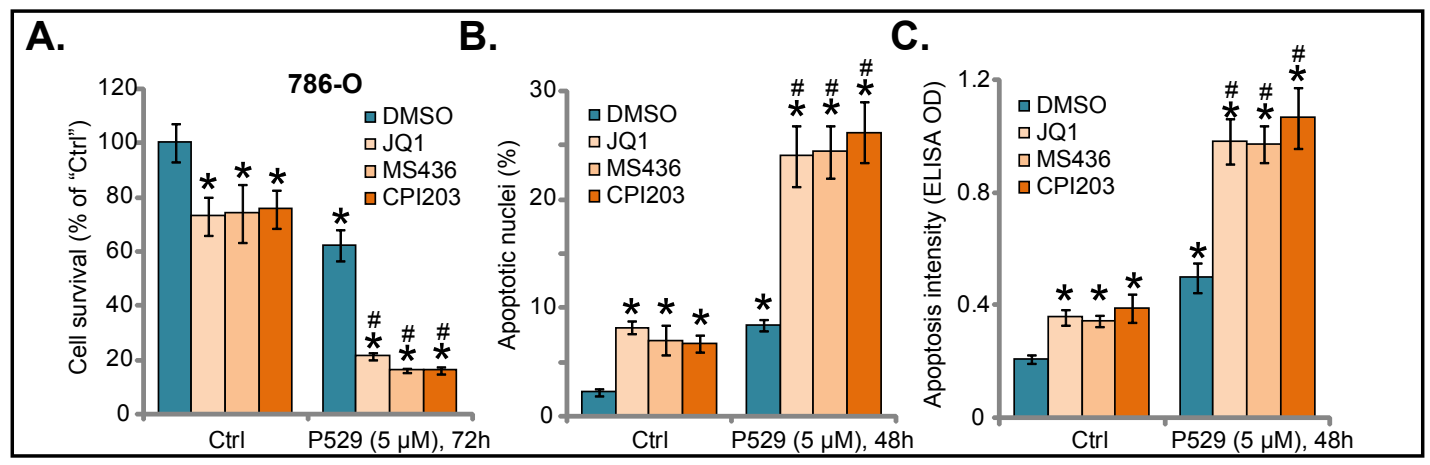

Fig. 3. BRD4 inhibitors facilitate Palomid 529-induced 786-0 cell apoptosis. 786-0 cells were pretreated for 30 min with JQ1 (1 $\mu \mathrm{M})$, MS436 (50 nM) or CPI203 (100 nM), followed by Palomid 529 ("P529", $5 \mu \mathrm{M}$ ) treatment, cells were then cultured for the applied time, cell survival was tested by the MTT assay (A); Cell apoptosis was tested by the assays mentioned in the text (B and C). For each assay, n=5. * $\mathrm{p}<0.05$ vs. "Ctrl" cells. ${ }^{\#}$ p $<0.05$ vs. "Palomid 529" only cells. In this figure, experiments were repeated four times, and similar results were obtained each time. 
To study the potential effect of c-Myc on Palomid 529-induced activity in RCC cells, shRNA method was applied again to knockdown c-Myc. As shown, each of the two applied c-Myc shRNAs ("-1/-2") led to over 95\% c-Myc protein reduction in 786-0 cells (Fig. 4E). Palomid 529 treatment again failed to affect c-Myc expression (Fig. 4E). Importantly, c-Myc silencing dramatically enhanced Palomid 529-induced 786-O cell viability reduction (Fig. 4F) and apoptosis (Fig. 4G). c-Myc shRNAs alone only induced minor cell viability reduction (Fig. 4F) and apoptosis (Fig. 4G). Thus, c-Myc-silenced 786-O cells show similar phenotype as the BRD4-shRNA cells. These results indicate that BRD4 silencing sensitizes Palomid 529-induced 786-0 cell apoptosis possibly via downregulating c-Myc.

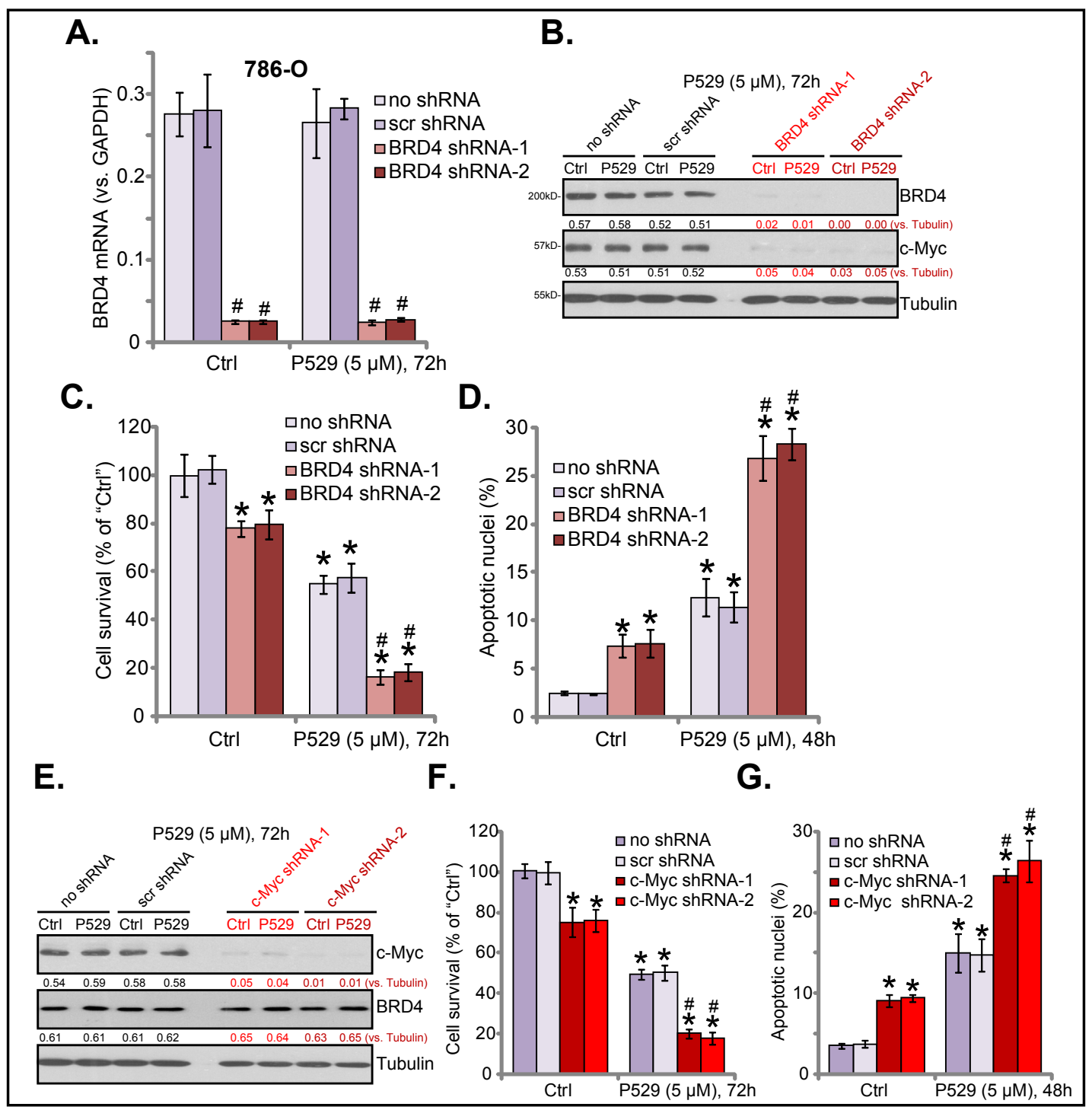

Fig. 4. BRD4 shRNA sensitizes Palomid 529-induced cytotoxicity in 786-0 cells. Stable 786-0 cells, with no shRNA (parental control cells), scramble control shRNA ("scr shRNA"), BRD4 shRNA ("-1/-2") or c-Myc shRNA ("-1/-2"), were treated with/out Palomid 529 ("P529", $5 \mu \mathrm{M}$ ) for applied time, BRD4 mRNA and listed proteins were tested by qRT-PCR assay (A, vs. GAPDH mRNA) and Western blotting assay (B and E), respectively; Cell viability was tested by the MTT assay ( $\mathrm{C}$ and F); Cell apoptosis was tested by the Hoechst apoptotic nuclei staining assay (D and G). For each assay, $n=5$. ${ }^{*} \mathrm{p}<0.05$ vs. "Ctrl" cells. ${ }^{\#} \mathrm{p}<0.05$ vs. "scr shRNA" cells. In this figure, experiments were repeated four times, and similar results were obtained each time. 
BRD4 over-expression inhibits Palomid 529-induced 786-O cell apoptosis

A BRD4 expression construct was transfected to 786-0 cells. Puromycin was applied to select stable cells. As shown in Fig. 5A, BRD4 mRNA level was significantly increased in cells with the construct (Fig. 5A). Western blotting assay results in Fig. 5B further confirmed expression of exogenous BRD4 (tagged with Flag) in the stable cells. c-Myc upregulation was detected as well in BRD4 over-expression cells (Fig. 5B). Significantly, Palomid 529-induced 786-O cell viability reduction (Fig. 5C) and apoptosis (Fig. 5D) were significantly inhibited in BRD4 over-expression cells. Thus, BRD4 over-expression inhibits Palomid 529-induced 786-0 cell apoptosis.

\section{Palomid 529 is cytotoxic to the primary human RCC cells}

We next studied the potential effect of Palomid 529 in the primary human RCC cells. A total of four different patient-derived primary human RCC cells were tested: namely "L1/L2/L3/L4". Among them, BRD4 protein expression was high in the "L1/L2" RCC cells, but relatively low in the "L3/L4" RCC cells (Fig. 6A). mTORC1 (reflected by "p-S6") and mTORC2 (reflected by "p-AKT Ser473") activation were high in "L1/L2/L3" RCC cells, but low in the "L4" RCC cells (Fig. 6A). Treatment with Palomid 529 dose-dependently inhibited cell viability in all the primary cancer cells (Fig. 6B). Yet, its cytotoxicity was most potent

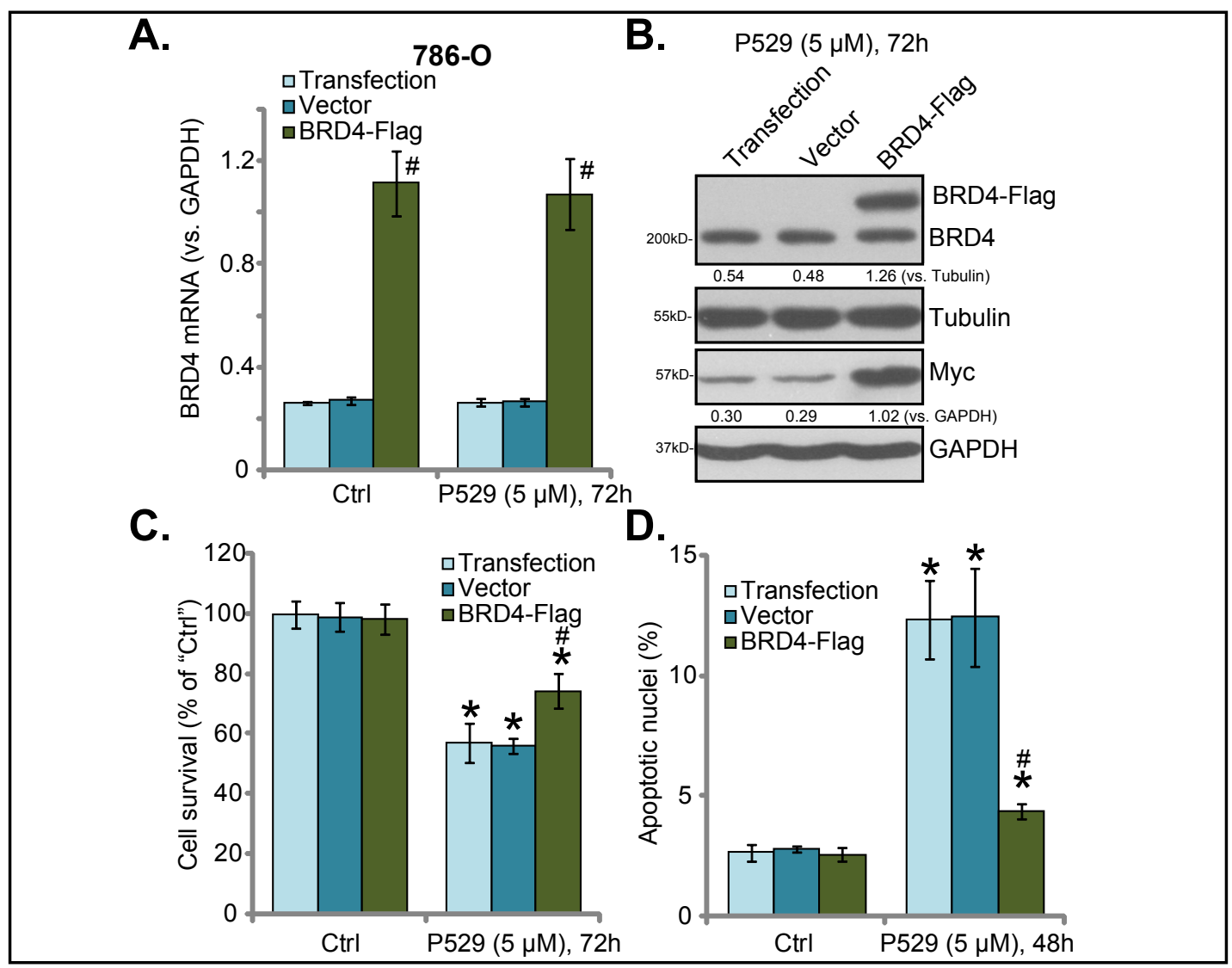

Fig. 5. BRD4 over-expression inhibits Palomid 529-induced 786-0 cell apoptosis. Stable 786-0 cells, with BRD4 expression construct ("pcDNA5-Flag-BRD4-WT-puro") or the empty vector ("pcDNA5-Flag-puro"), as well as the control cells with transfection reagents ("Transfection"), were treated with/out Palomid 529 ("P529", $5 \mu \mathrm{M}$ ) for applied time, expression of BRD4 mRNA and listed proteins were tested by qRT-PCR assay (A, vs. GAPDH mRNA) and Western blotting assay (B), respectively; Cell survival was tested by the MTT assay (C); Cell apoptosis was tested by the Hoechst apoptotic nuclei staining assay (D). For each assay, $n=5$. * $\mathrm{p}<0.05$ vs. "Ctrl" cells. ${ }^{*} \mathrm{p}<0.05$ vs. "Vector" cells. In this figure, experiments were repeated three times, and similar results were obtained each time. 
in the "L3" RCC cells (IC-50=1.37 $\pm 0.11 \mu \mathrm{M}$, Fig. 6B), which had lowest BRD4 expression but highest mTORC1/2 activation (Fig. 6A). "L2" RCC cells, with highest BRD4 expression (Fig. 6A), were resistant to Palomid 529, (IC-50 over $50 \mu \mathrm{M}$, Fig. 6B). When analyzing cell apoptosis, we show that Palomid $529(5 \mu \mathrm{M})$ induced significant apoptosis in "L3" RCC cells (Fig. 6C). Thus, Palomid 529 is cytotoxic to the primary human RCC cells. Its sensitivity is negatively correlated with BRD4 expression in the primary cancer cells.

\section{JQ1 facilitates Palomid 529-induced anti-tumor activity in vivo}

The potential effect of Palomid 529 in vivo was tested. $786-0$ cells $\left(5 \times 10^{6}\right.$ cells per mouse) were inoculated via s.c. injection to the severe combined immunodeficiency (SCID) mice. Tumor growth curve results show that Palomid 529 (100 mg/kg/2 d, i.p., for 18 days) $[20,21]$ administration significantly inhibited 786-0 xenograft tumor growth in SCID mice (Fig. 7A). The estimated daily tumor growth was calculated by: (tumor volume at Day-42tumor volume at Day-0)/42. Results show again that Palomid 529 administration inhibited 786-0 xenograft tumor growth. At Day-42, the tumors in Palomid 529 treatment group were significantly lighter than the vehicle control tumors (Fig. 7C). Remarkably, co-administration of JQ1 (50 mg/kg/2 d, i.p., for 18 days) [43] significantly enhanced Palomid 529-induced anti-786-0 tumor activity in vivo (Fig. 7A-C). Treatment with JQ1 alone exerted only minor inhibition on 786-0 tumor growth (Fig. 7A-C).

The body weights of the experimental animals were not significantly different between the groups (Fig. 7D), indicating that the single or combination treatments were relatively safe to the animals. At Day-6, three hours after the drug administration, one tumor of each group was isolated. Expression of signaling proteins in tumor lysates were tested. As shown in Fig. 7E, administration of Palomid 529 led to dramatic inhibition of p-S6 (Ser-235/236) and p-AKT (Ser-473), indicating mTORC1/2 dual inhibition in vivo. Co-administration of JQ1 failed to affect p-AKT nor p-S6 in the tumor tissues (Fig. 7E).

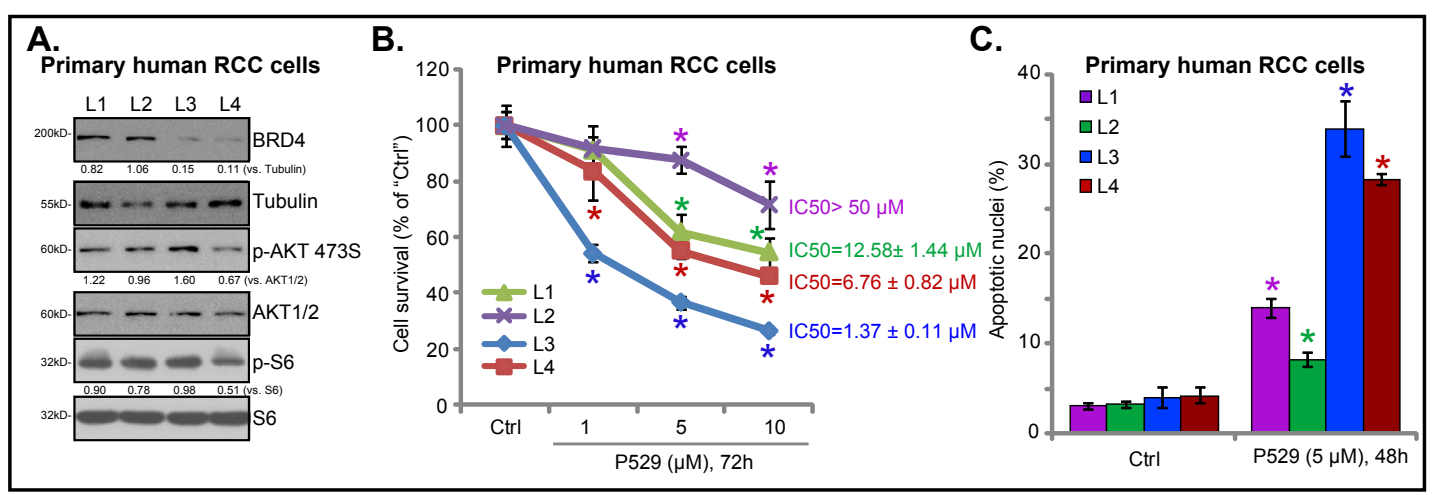

Fig. 6. Palomid 529 is cytotoxic to primary human RCC cells. Expression of listed proteins in the four different primary human RCC cells ("L1/L2/L3/L4") was tested by Western blotting assay (A). The primary human RCC cells were either left untreated ("Ctrl") or treated with applied concentration (0.1-10 $\mu \mathrm{M})$ of Palomid 529 ("P529"), cells were then cultured for the applied time, cell survival and apoptosis were tested by MTT assay (B) and Hoechst apoptotic nuclei assay (C), respectively. For each assay, n=5. * p<0.05 vs. "Ctrl" cells. In this figure, experiments were repeated three times, and similar results were obtained each time. 


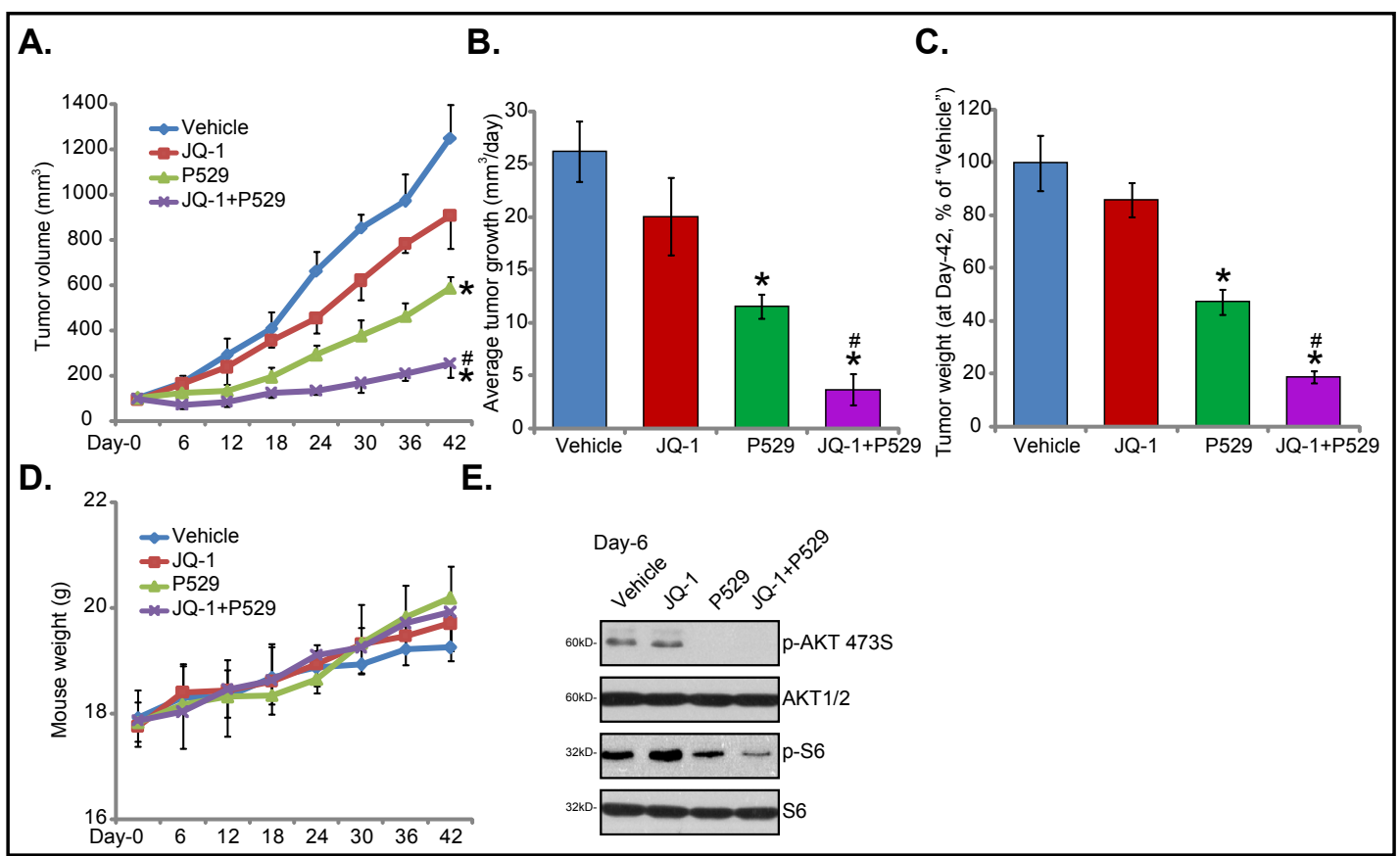

Fig. 7. JQ1 facilitates Palomid 529-induced anti-tumor activity in vivo. The 786-0 xenograft tumor-bearing SCID mice were treated with vehicle control ("Vehicle"), Palomid 529 ("P529", 100 mg/kg/2 d, i.p., for 18 days) and/or JQ1 (50 mg/kg/2 d, i.p., for 18 days), the tumor volume (A) and mice body weight (D) were recorded every 6 days for a total of 42 days; Estimated daily tumor growth was calculated as described (B); At Day-42, tumors of each group were isolated and weighted (C); At Day-6, three hours after the drug administration, one tumor of each group was isolated, listed signaling proteins were tested by Western blotting assay of tumor lysates (E). For each group, $n=10$. * $\mathrm{p}<0.05$ vs. "Vehicle" group. \# p<0.05 vs. "P529" only group.

\section{Discussion}

Inhibition, silencing or loss-of-function mutation of mTOR can efficiently induce RCC cell death and apoptosis. Everolimus and other mTORC1 inhibitors have been approved by FDA for the treatment of certain advanced RCCs $[3,5]$. The clinical application of these mTORC1 inhibitors, however, could have several drawbacks (see Introduction). Recent studies have implied that concurrent blockage of mTORC1 and mTORC2 is more efficient than mTORC1 inhibitors in inhibiting RCC cells $[27,29]$. One possible reason could be that mTORC2 is as important as mTORC1 for RCC cell progression [28, 44, 45].

Here, we show that Palomid 529 not only disassembled mTORC1 (mTOR-Raptor complex) and mTORC2 (mTOR-Rictor complex), but also de-phosphorylated mTORC1/2 substrates in 786-0 RCC cells. Palomid 529 exerted cytotoxic, anti-proliferative and proapoptotic activities to 786-O cells and the primary human RCC cells. In vivo, Palomid 529 i.p. administration potently inhibited 786-0 xenograft tumor growth in SCID mice. Thus, Palomid 529 could be further tested as a promising anti-RCC agent.

Recent studies have implied that BRD4 is essential for activation and expression of several key oncogenes. It can promote cell proliferation, cell-cycle progression, survival and apoptosis resistance [46]. Several of these genes have been indentified, including cyclin D1, $B c l-2$ and $c-M y c[38,47-51]$. Our results show that BRD4 silencing by targeted shRNAs led to c-Myc downregulation in 786-0 cells. Reversely, c-Myc upregulation was detected in BRD4 over-expression cells. Thus, BRD4 is required for c-Myc expression in RCC cells.

We propose that BRD4 could be a primary resistant factor of Palomid 529. First, pharmacologic inhibition of BRD4 enhanced Palomid 529-induced 786-0 cell death KARGER 


\section{Cellular Physiology Cell Physiol Biochem 2018;50:640-653 \begin{tabular}{ll|l} 
DOI: 10.1159/000494185 & $\begin{array}{l}\text { O 2018 The Author(s). Published by S. Karger AG, Basel } \\
\text { www.karger.com/cpb }\end{array}$ \\
\hline and Biochemistry
\end{tabular}}

and apoptosis. Second, shRNA-mediated knockdown of BRD4 also facilitated Palomid 529-induced 786-0 cell apoptosis. Reversely, exogenous over-expression of BRD4 attenuated Palomid 529's cytotoxicity in 786-0 cells. Further, Palomid 529's cytotoxicity to the primary human RCC cells was negatively correlated with BRD4 expression level. Importantly, Palomid 529-induced anti-786-0 tumor activity in vivo was sensitized with co-administration of JQ1. Inhibition of BRD4 could be a fine strategy to sensitize Palomid 529 in RCC cells. Previous studies have established synergistic to additive effects between mTORC1 inhibitors and bromodomain protein inhibition in various human cancers [52-54]. For example, Lee et al., reported the synergistic anti-osteosarcoma activity by the BRD4 inhibitor JQ1 and rapamycin [54]. Berenguer-Daize et al., reported that OTX015 (a novel BET inhibitor) and the MTORC1 inhibitor everolimus synergisticly inhibited glioblastoma cell growth [52]. In the breast cancer cells, BRD4-Myc inhibition could significantly sensitize everolimus [53]. Therefore, BRD4-dependent resistance in RCC cells could be a primarily mTORC1-dependent effect, although the underlying mechanisms warrant further characterizations.

\section{Conclusion}

Palomid 529 blocks mTORC1/2 activation, inhibiting RCC cell growth in vitro and in vivo. BRD4 could be the primary resistance factor of Palomid 529 in RCC cells. Everolimus has been approved by FDA to treat patients with advanced kidney cancer after failure of either sunitinib or sorafenib treatment $[3,5]$. Our results suggest that Palomid 529 might possibly be an alternative of rapalogs for RCC treatment.

\section{Acknowledgements}

All authors conceived the idea and designed the work, contributed to acquisition of data. This work was supported by the Natural Science Foundation of China (81371513 and 81401386). The funders had no role in study design, data collection and analysis, decision to publish, or preparation of the manuscript.

\section{Disclosure Statement}

No conflict of interests exists.

\section{References}

-1 Siegel RL, Miller KD, Jemal A: Cancer Statistics, 2017. CA Cancer J Clin 2017;67:7-30.

-2 Siegel RL, Miller KD, Jemal A: Cancer statistics, 2016. CA Cancer J Clin 2016;66:7-30.

-3 Pal SK, Quinn DI: Differentiating mTOR inhibitors in renal cell carcinoma. Cancer Treat Rev 2013;39:709719.

4 Barthelemy P, Hoch B, Chevreau C, Joly F, Laguerre B, Lokiec F, Duclos B: mTOR inhibitors in advanced renal cell carcinomas: from biology to clinical practice. Crit Rev Oncol Hematol 2013;88:42-56.

$>5$ Husseinzadeh HD, Garcia JA: Therapeutic rationale for mTOR inhibition in advanced renal cell carcinoma. Curr Clin Pharmacol 2011;6:214-221.

6 Zhao W, Peng F, Shu M, Liu H, Hou X, Wang X, Ye J, Zhao B, Wang K, Zhong C, Xue L, Gao M, Liu Y, Zhao S: Isogambogenic Acid Inhibits the Growth of Glioma Through Activation of the AMPK-mTOR Pathway. Cell Physiol Biochem 2017;44:1381-1395.

7 Zhu H, Liu Q Tang J, Xie Y, Xu X, Huang R, Zhang Y, Jin K, Sun B: Alpha1-ACT Functions as a Tumour Suppressor in Hepatocellular Carcinoma by Inhibiting the PI3K/AKT/mTOR Signalling Pathway via Activation of PTEN. Cell Physiol Biochem 2017;41:2289-2306. 


\section{Cellular Physiology Cell Physiol Biochem 2018;50:640-653 \begin{tabular}{ll|l} 
DOI: 10.1159/000494185 & $\begin{array}{l}\text { O 2018 The Author(s). Published by S. Karger AG, Basel } \\
\text { www.karger.com/cpb }\end{array}$ \\
\hline and Biochemistry
\end{tabular}}

Xing et al.: BRD4 Inhibition Sensitizes Palomid 529 in RCC Cells

8 Saxton RA, Sabatini DM: mTOR Signaling in Growth, Metabolism, and Disease. Cell 2017;168:960-976.

-9 Dancey J: mTOR signaling and drug development in cancer. Nat Rev Clin Oncol 2010;7:209-219.

10 Sabatini DM: mTOR and cancer: insights into a complex relationship. Nat Rev Cancer 2006;6:729-734.

11 Sarbassov DD, Guertin DA, Ali SM, Sabatini DM: Phosphorylation and regulation of Akt/PKB by the rictormTOR complex. Science 2005;307:1098-1101.

12 Sarbassov DD, Ali SM, Kim DH, Guertin DA, Latek RR, Erdjument-Bromage H, Tempst P, Sabatini DM: Rictor, a novel binding partner of mTOR, defines a rapamycin-insensitive and raptor-independent pathway that regulates the cytoskeleton. Curr Biol 2004;14:1296-1302.

-13 Fruman DA, Rommel C: PI3K and cancer: lessons, challenges and opportunities. Nat Rev Drug Discov 2014;13:140-156.

14 Petricoin EF, 3rd, Espina V, Araujo RP, Midura B, Yeung C, Wan X, Eichler GS, Johann DJ, Jr., Qualman S, Tsokos M, Krishnan K, Helman LJ, Liotta LA: Phosphoprotein pathway mapping: Akt/mammalian target of rapamycin activation is negatively associated with childhood rhabdomyosarcoma survival. Cancer Res 2007;67:3431-3440.

15 Shi Y, Yan H, Frost P, Gera J, Lichtenstein A: Mammalian target of rapamycin inhibitors activate the AKT kinase in multiple myeloma cells by up-regulating the insulin-like growth factor receptor/insulin receptor substrate-1/phosphatidylinositol 3-kinase cascade. Mol Cancer Ther 2005;4:1533-1540.

16 Chen XG, Liu F, Song XF, Wang ZH, Dong ZQ, Hu ZQ Lan RZ, Guan W, Zhou TG, Xu XM, Lei H, Ye ZQ, Peng EJ, Du LH, Zhuang QY: Rapamycin regulates Akt and ERK phosphorylation through mTORC1 and mTORC2 signaling pathways. Mol Carcinog 2010;49:603-610.

-17 Zhou HY, Huang SL: Current development of the second generation of mTOR inhibitors as anticancer agents. Chin J Cancer 2012;31:8-18.

18 Vilar E, Perez-Garcia J, Tabernero J: Pushing the envelope in the mTOR pathway: the second generation of inhibitors. Mol Cancer Ther 2011;10:395-403.

-19 Lin F, Buil L, Sherris D, Beijnen JH, van Tellingen O: Dual mTORC1 and mTORC2 inhibitor Palomid 529 penetrates the blood-brain barrier without restriction by ABCB1 and ABCG2. Int J Cancer 2013;133:12221233.

20 Gravina GL, Marampon F, Petini F, Biordi L, Sherris D, Jannini EA, Tombolini V, Festuccia C: The TORC1/ TORC2 inhibitor, Palomid 529, reduces tumor growth and sensitizes to docetaxel and cisplatin in aggressive and hormone-refractory prostate cancer cells. Endocr Relat Cancer 2011;18:385-400.

21 Xue Q Hopkins B, Perruzzi C, Udayakumar D, Sherris D, Benjamin LE: Palomid 529, a novel smallmolecule drug, is a TORC1/TORC2 inhibitor that reduces tumor growth, tumor angiogenesis, and vascular permeability. Cancer Res 2008;68:9551-9557.

22 Wu X, Liu D, Gao X, Xie F, Tao D, Xiao X, Wang L, Jiang G, Zeng F: Inhibition of BRD4 Suppresses Cell Proliferation and Induces Apoptosis in Renal Cell Carcinoma. Cell Physiol Biochem 2017;41:1947-1956.

23 Devaiah BN, Singer DS: Two faces of brd4: mitotic bookmark and transcriptional lynchpin. Transcription 2013;4:13-17.

-24 Hong SH, Eun JW, Choi SK, Shen Q, Choi WS, Han JW, Nam SW, You JS: Epigenetic reader BRD4 inhibition as a therapeutic strategy to suppress E2F2-cell cycle regulation circuit in liver cancer. Oncotarget 2016;7:32628-32640.

-25 Gao X, Wu X, Zhang X, Hua W, Zhang Y, Maimaiti Y, Gao Z: Inhibition of BRD4 suppresses tumor growth and enhances iodine uptake in thyroid cancer. Biochem Biophys Res Commun 2016;469:679-685.

-26 Zheng B, Zhu H, Gu D, Pan X, Qian L, Xue B, Yang D, Zhou J, Shan Y: MiRNA-30a-mediated autophagy inhibition sensitizes renal cell carcinoma cells to sorafenib. Biochem Biophys Res Commun 2015;459:234239.

-27 Zheng B, Mao JH, Qian L, Zhu H, Gu DH, Pan XD, Yi F, Ji DM: Pre-clinical evaluation of AZD-2014, a novel mTORC1/2 dual inhibitor, against renal cell carcinoma. Cancer Lett 2015;357:468-475.

28 Zheng B, Mao JH, Li XQ, Qian L, Zhu H, Gu DH, Pan XD: Over-expression of DNA-PKcs in renal cell carcinoma regulates mTORC2 activation, HIF-2alpha expression and cell proliferation. Sci Rep 2016;6:29415.

29 Pan XD, Gu DH, Mao JH, Zhu H, Chen X, Zheng B, Shan Y: Concurrent inhibition of mTORC1 and mTORC2 by WYE-687 inhibits renal cell carcinoma cell growth in vitro and in vivo. PLoS One 2017;12:e0172555.

-30 Cao C, Rioult-Pedotti MS, Migani P, Yu CJ, Tiwari R, Parang K, Spaller MR, Goebel DJ, Marshall J: Impairment of TrkB-PSD-95 signaling in Angelman syndrome. PLoS Biol 2013;11:e1001478. 


\section{Cellular Physiology Cell Physiol Biochem 2018;50:640-653 \begin{tabular}{ll|l} 
DOI: 10.1159/000494185 & $\begin{array}{l}\text { O } 2018 \text { The Author(s). Published by S. Karger AG, Basel } \\
\text { www.kargercom/cpb }\end{array}$
\end{tabular}

Xing et al.: BRD4 Inhibition Sensitizes Palomid 529 in RCC Cells

31 Cao C, Huang X, Han Y, Wan Y, Birnbaumer L, Feng GS, Marshall J, Jiang M, Chu WM: Galpha(i1) and Galpha(i3) are required for epidermal growth factor-mediated activation of the Akt-mTORC1 pathway. Sci Signal 2009;2:ra17.

-32 Feng Q Zhang Z, Shea MJ, Creighton CJ, Coarfa C, Hilsenbeck SG, Lanz R, He B, Wang L, Fu X, Nardone A, Song Y, Bradner J, Mitsiades N, Mitsiades CS, Osborne CK, Schiff R, O'Malley BW: An epigenomic approach to therapy for tamoxifen-resistant breast cancer. Cell Res 2014;24:809-819.

-33 Sun C, Huang C, Li S, Yang C, Xi Y, Wang L, Zhang F, Fu Y, Li D: Hsa-miR-326 targets CCND1 and inhibits nonsmall cell lung cancer development. Oncotarget 2016;7:8341-8359.

-34 Gwinn DM, Shackelford DB, Egan DF, Mihaylova MM, Mery A, Vasquez DS, Turk BE, Shaw RJ: AMPK phosphorylation of raptor mediates a metabolic checkpoint. Mol Cell 2008;30:214-226.

-35 Wang YH, Sui YN, Yan K, Wang LS, Wang F, Zhou JH: BRD4 promotes pancreatic ductal adenocarcinoma cell proliferation and enhances gemcitabine resistance. Oncol Rep 2015;33:1699-1706.

-36 Zanellato I, Colangelo D, Osella D: JQ1, a BET inhibitor, synergizes with cisplatin and induces apoptosis in highly chemoresistant malignant pleural mesothelioma cells. Curr Cancer Drug Targets 2017; D0I:10.2174 /1568009617666170623101722.

37 Yao W, Yue P, Khuri FR, Sun SY: The BET bromodomain inhibitor, JQ1, facilitates c-FLIP degradation and enhances TRAIL-induced apoptosis independent of BRD4 and c-Myc inhibition. Oncotarget 2015;6:3466934679.

38 Zhang L, Tong Y, Zhang X, Pan M, Chen S: Arsenic sulfide combined with JQ1, chemotherapy agents, or celecoxib inhibit gastric and colon cancer cell growth. Drug Des Devel Ther 2015;9:5851-5862.

-39 Zhang G, Plotnikov AN, Rusinova E, Shen T, Morohashi K, Joshua J, Zeng L, Mujtaba S, Ohlmeyer M, Zhou MM: Structure-guided design of potent diazobenzene inhibitors for the BET bromodomains. J Med Chem 2013;56:9251-9264.

\$0 Knudsen KJ, Rehn M, Hasemann MS, Rapin N, Bagger FO, Ohlsson E, Willer A, Frank AK, Sondergaard E, Jendholm J, Thoren L, Lee J, Rak J, Theilgaard-Monch K, Porse BT: ERG promotes the maintenance of hematopoietic stem cells by restricting their differentiation. Genes Dev 2015;29:1915-1929.

-41 Delmore JE, Issa GC, Lemieux ME, Rahl PB, Shi J, Jacobs HM, Kastritis E, Gilpatrick T, Paranal RM, Qi J, Chesi M, Schinzel AC, McKeown MR, Heffernan TP, Vakoc CR, Bergsagel PL, Ghobrial IM, Richardson PG, Young RA, Hahn WC, et al.: BET bromodomain inhibition as a therapeutic strategy to target c-Myc. Cell 2011;146:904917.

42 Zhang H, Gao P, Fukuda R, Kumar G, Krishnamachary B, Zeller KI, Dang CV, Semenza GL: HIF-1 inhibits mitochondrial biogenesis and cellular respiration in VHL-deficient renal cell carcinoma by repression of C-MYC activity. Cancer Cell 2007;11:407-420.

43 Zuber J, Shi J, Wang E, Rappaport AR, Herrmann H, Sison EA, Magoon D, Qi J, Blatt K, Wunderlich M, Taylor MJ, Johns C, Chicas A, Mulloy JC, Kogan SC, Brown P, Valent P, Bradner JE, Lowe SW, Vakoc CR: RNAi screen identifies Brd4 as a therapeutic target in acute myeloid leukaemia. Nature 2011;478:524-528.

44 Toschi A, Lee E, Gadir N, Ohh M, Foster DA: Differential dependence of hypoxia-inducible factors 1 alpha and 2 alpha on mTORC1 and mTORC2. J Biol Chem 2008;283:34495-34499.

$\$ 45$ Figlin RA, Kaufmann I, Brechbiel J: Targeting PI3K and mTORC2 in metastatic renal cell carcinoma: new strategies for overcoming resistance to VEGFR and mTORC1 inhibitors. Int J Cancer 2013;133:788-796.

-46 Wang CY, Filippakopoulos P: Beating the odds: BETs in disease. Trends Biochem Sci 2015;40:468-479.

47 Qiu H, Li J, Clark LH, Jackson AL, Zhang L, Guo H, Kilgore JE, Gehrig PA, Zhou C, Bae-Jump VL: JQ1 suppresses tumor growth via PTEN/PI3K/AKT pathway in endometrial cancer. Oncotarget 2016;7:6680966821.

48 Wang H, Sharma L, Lu J, Finch P, Fletcher S, Prochownik EV: Structurally diverse c-Myc inhibitors share a common mechanism of action involving ATP depletion. Oncotarget 2015;6:15857-15870.

49 Coude MM, Braun T, Berrou J, Dupont M, Bertrand S, Masse A, Raffoux E, Itzykson R, Delord M, Riveiro ME, Herait P, Baruchel A, Dombret H, Gardin C: BET inhibitor OTX015 targets BRD2 and BRD4 and decreases c-MYC in acute leukemia cells. Oncotarget 2015;6:17698-17712.

50 Andrews FH, Singh AR, Joshi S, Smith CA, Morales GA, Garlich JR, Durden DL, Kutateladze TG: Dual-activity PI3K-BRD4 inhibitor for the orthogonal inhibition of MYC to block tumor growth and metastasis. Proc Natl Acad Sci U S A 2017;114:E1072-E1080.

51 Wang L, Wu X, Wang R, Yang C, Li Z, Wang C, Zhang F, Yang P: BRD4 inhibition suppresses cell growth, migration and invasion of salivary adenoid cystic carcinoma. Biol Res 2017;50:19. 
52 Berenguer-Daize C, Astorgues-Xerri L, Odore E, Cayol M, Cvitkovic E, Noel K, Bekradda M, MacKenzie S, Rezai K, Lokiec F, Riveiro ME, Ouafik L: OTX015 (MK-8628), a novel BET inhibitor, displays in vitro and in vivo antitumor effects alone and in combination with conventional therapies in glioblastoma models. Int J Cancer 2016;139:2047-2055.

53 Bihani T, Ezell SA, Ladd B, Grosskurth SE, Mazzola AM, Pietras M, Reimer C, Zinda M, Fawell S, D’Cruz CM: Resistance to everolimus driven by epigenetic regulation of MYC in ER+ breast cancers. Oncotarget 2015;6:2407-2420.

54 Lee DH, Qi J, Bradner JE, Said JW, Doan NB, Forscher C, Yang H, Koeffler HP: Synergistic effect of JQ1 and rapamycin for treatment of human osteosarcoma. Int J Cancer 2015;136:2055-2064. 